\title{
A New Approach to Maximum Power Point Tracking for Sudden Changes in Irradiance in Photovoltaic Systems
}

\author{
Slamet ${ }^{1,2}$, Rasli bin AbdGhani ${ }^{2 *}$ and Fuminori Kobayashi ${ }^{2}$ \\ 'Research and Development Center for Electricity, New Renewable Energy, and Energy Conservation Technology \\ (P3TKEBTKE) Jl. Ciledug Raya Kav. 109 Cipulir Kebayoran Lama, Jakarta 12230, INDONESIA \\ ${ }^{2}$ Ministry of High Education of Malaysia (MOHE), Malaysia - Japan International Institute of Technology (MJIIT), \\ University Teknologi Malaysia Kuala Lumpur, JalanSemarak, 54100 Kuala Lumpur, MALAYSIA \\ slam_mjiit@yahoo.com, rasli.kl@utm.my,kobayashi.kl@utm.my
}

\begin{abstract}
Background/Objective: This paper presents a new digital control approach to track the Maximum Power Point (MPPT) for Potovoltaic (PV) systems. A photovoltaic power generation system requires an effective controller to overcome sudden changes to irradiance and to maximize its efficiency. Methods/Statistical Analysis: A new approach to MPPT based on voltage control was proposed, while a PI (Proportional Integral) controller was combined with the boost converter to adapt the duty cycle. Findings: The input voltage reference was adaptively perturbed with variable steps until the maximum power was reached. A state-space model was derived through the averaging method, with the control input being the duty ratio to regulate the pulse width modulator on the DC-DC boost converter. The proposed control scheme eliminated steady state oscillations around the working point area of the PV panel when there were rapid changes to the irradiance. Applications/Improvements: Furthermore, the PV system became more efficient, as proven by the sudden change in the radiation conditions for 0.3 seconds, where approximately $30 \%$ of energy could be saved.
\end{abstract}

Keywords: Averaging Model, Boost Converter, Combination IP, Irradiance, New MPPT, Photovoltaic

\section{Introduction}

Solar power is becoming increasingly important as a source of renewable energy as it is clean energy, requires less maintenance, and so forth. The output Power of Photovoltaic (PV) arrays always changes according to weather conditions, i.e., irradiance and atmospheric temperature. In many cases, PV systems have their shortcomings when it comes to the conversion of solar radiance into electrical energy. The University of Tokyo tested more than 71 Japanese PV systems, all of which showed losses of up to $25 \%^{1}$. Therefore, Maximum Power Point Tracking (MPPT) has been used to improve the energy efficiency. Some techniques have been proposed to track the Maximum Power Point (MPP) and MPPT-based Perturbation and Observation ( $\mathrm{P} \& \mathrm{O})$ methods have been implemented. The $\mathrm{P} \& \mathrm{O}$ and hill climbing methods were applied for the MPPT controller of a two-stage PV grid-connected converter system. Their performance was evaluated and compared through theoretical analysis and digital simulation. P\&O MPPT method exhibits fast dynamic performance and well regulated PV output voltage, which is more suitable than hill climbing method for PV system ${ }^{2}$.

Nevertheless, steady state oscillations have always appeared in both methods due to the perturbation ${ }^{3}$. 
$A$ boost converter, also known as a step-up converter, is considered to be the most beneficial component in solar cell applications because of its simplicity, low cost, and high efficiency. An incremental conductance method has been developed to overcome the drawbacks of the P\&O method. This method is capable of achieving better performance results with varying irradiance, temperature, and uncertain charges. It also takes a shorter time to reach the optimal power operating point. In addition, oscillations around the operating point of the MPP can also be reduced and eliminated.

The MPPT algorithm, which is based on the incremental conductance method, regulates the PV voltage ${ }^{4,5}$. The steady state oscillations should eliminate the error at the MPP. However, the slope value of the error curve is seldom null due to the resolution of the digital implementation. The Incremental Conductance Method (ICM) is better than the $\mathrm{P} \& \mathrm{O}$ technique in tracking the MPP, where the advancements of Digital Signal Processors (DSPs), both ICM and P\&O, can be easily implemented ${ }^{5}$.

This paper proposed improvements to the tracking accuracy and dynamic performance under sudden changes in irradiance conditions.

\section{Methodology}

\subsection{Photovoltaic/ Solar Cell System Models}

There are two types of solar cell models that are used for different purposes. The first is a static model, which does not use the transfer function of a Low Pass Filter (LPF), while the second is a dynamic model of a PV-boost system based on the integration of a solar cell model with an LPF to carry out simulations of a solar power plant in real conditions, which is expected in designing a new MPPT algorithm. The two modelling schemes are presented, respectively, in the following sections ${ }^{7}$.

The exponential equation that was used to build the solar cell model was derived from the laws of physics for the p-n junction, which is generally accepted for the presentation of cell characteristics. For the modelling of the PV statics, the equivalent circuit of the PV system ${ }^{7}$ in Figure 1 was adopted. The characteristic of the I-V curve can be modelled as proposed in ${ }^{6-9}$.

$$
I=I_{p h}-I_{s}\left(\exp \frac{q\left(V_{P V}+I R_{s}\right)}{N K T}-1\right)-\frac{\left(V_{P V}+I R_{s}\right)}{R_{s h}}
$$

Where $V_{\mathrm{PV}}$ is the PV voltage, $I_{\mathrm{PV}}$ is the current, $I_{\mathrm{ph}}$ is the photon current, $I_{\mathrm{s}}$ is the reverse saturation current of the diode, $N$ is the ideality factor of the diode, $T$ is the solar cell arrays in Kelvin $(\mathrm{K})$, the value of the electron charge (q) is $1.60217646 \times 10^{-19} \mathrm{C}$, and the Boltzmann constant, $K$ is $1.3806503 \times 10^{-23} \mathrm{~J} / \mathrm{K}$. Moreover, $R_{\mathrm{s}}$ and $R_{\mathrm{sh}}$ are the equivalent series and shunt resistance of the solar cell array, respectively. The PV voltage and current of the solar cell were strongly influenced by the environmental conditions, i.e. solar radiation and cell temperature. From Equation (1), the irradiance $\lambda$, the temperature coefficient

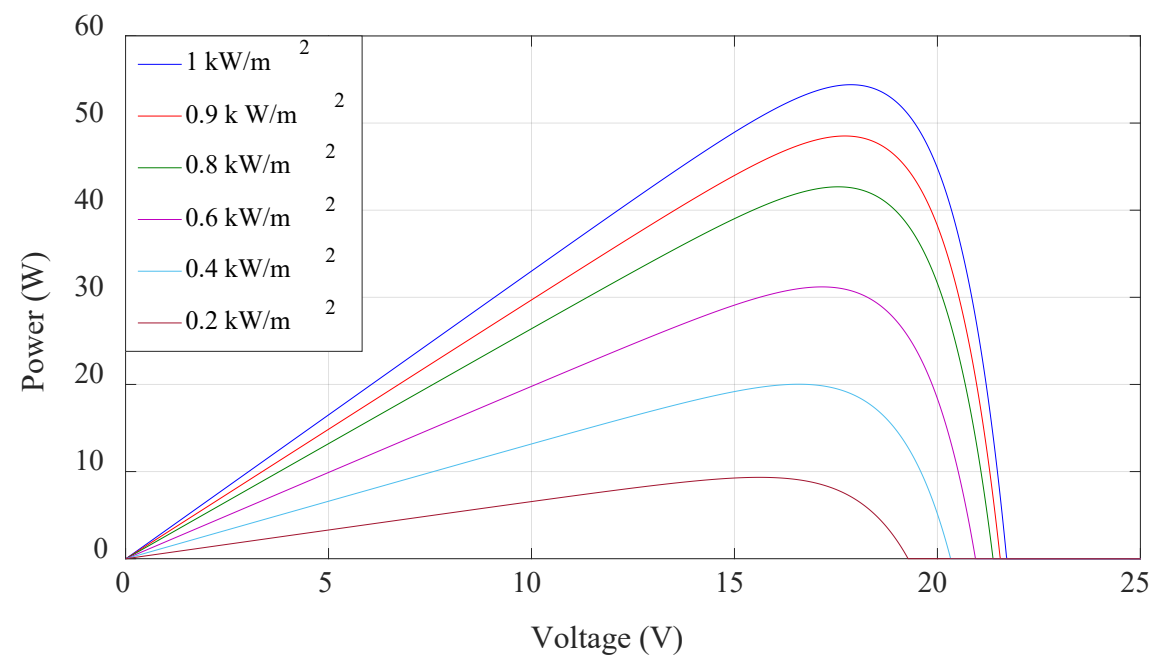

Figure 1. P-V characteristics of solar cell under different irradiances $\left(\right.$ at $\left.25^{\circ} \mathrm{C}\right)$. 
of the short circuit current $K_{\mathrm{t}}$, at a temperature of $25{ }^{\circ} \mathrm{C}$ can be derived ${ }^{7}$.

$$
I_{p h}=\left[I_{S C}+K_{t}(T-298)\right] \frac{\lambda}{100}
$$

In Equation (2), the current generated by the photons is directly proportional to the solar radiation. The effect of changes to the solar radiation on the PV characteristic curve is shown in Figure 2. In a short circuit current, the voltage is zero or the circuit voltage is open at the time so that no current flows ${ }^{10}$. Figure 1 shows the $\mathrm{P}-\mathrm{V}$ curve characteristics at a temperature of $25^{\circ} \mathrm{C}$ under different irradiance rates. The generated current is shown to be increasing with the irradiance level.

\subsection{Proposed Design of a New Approach}

This paper proposed a new approach to an improved MPPT by using a dual controller to compensate for the output voltage. The controller used a modified Integral Proportional (IP) MPPT and PI controllers for an inner controller on the boost converter, which consisted of two parts:

$$
\begin{aligned}
& \text { Proportional }(P) \text { part: } u_{P}(t)=K_{p}\left(y_{s}(t)-y(t)\right) \\
& \text { Integral }(I) \text { part: } u_{I}(t)=\frac{K_{p}}{\tau_{i}} \int_{0}^{t}\left(y_{s}(\tau)-y(\tau)\right) d \tau
\end{aligned}
$$

The PI controller output was equal to the sum of the two parts:

$$
\begin{gathered}
u(t)=u_{P}(t)+u_{I}(t) \\
u_{I}(t)=K_{p}\left(y_{s}(t)-y(t)\right) \frac{K_{p}}{\tau_{i}} \int_{0}^{t}\left(y_{s}(\tau)-y(\tau)\right) d \tau \\
G_{p}(s)=\frac{u(s)}{y_{s}(s)-y(s)} \\
G_{p}(s)=k_{p}+\frac{k_{p}}{\tau_{i} s}
\end{gathered}
$$

The output controller was equal to the sum of the two parts:

$$
\begin{gathered}
u(t)=u_{I}(t)-u_{P}(t) \\
u(t)=\frac{K_{p}}{\tau_{i}} \int_{0}^{t}\left(y_{s}(\tau)-y(\tau)\right) d \tau-K_{p}\left(y_{s}(t)-y(t)\right)
\end{gathered}
$$

where variables of the controller $y_{s}(t), y(t)$, and $u(t)$ were the set point, output process, and output of the IP controller, respectively. The component variables $k_{\mathrm{c}}$, and $\tau_{\mathrm{i}}$ were the proportional gain and integrator, respectively. In the experiment, their use as the controller, set point and controller parameters, $k_{\mathrm{c}}$ and $\tau_{\mathrm{i}}$, were set by the user. The input and output of the IP controller were $y_{s}(t)-y(t)$ and $u(t)$, respectively. Thus, the IP controller was as follows.

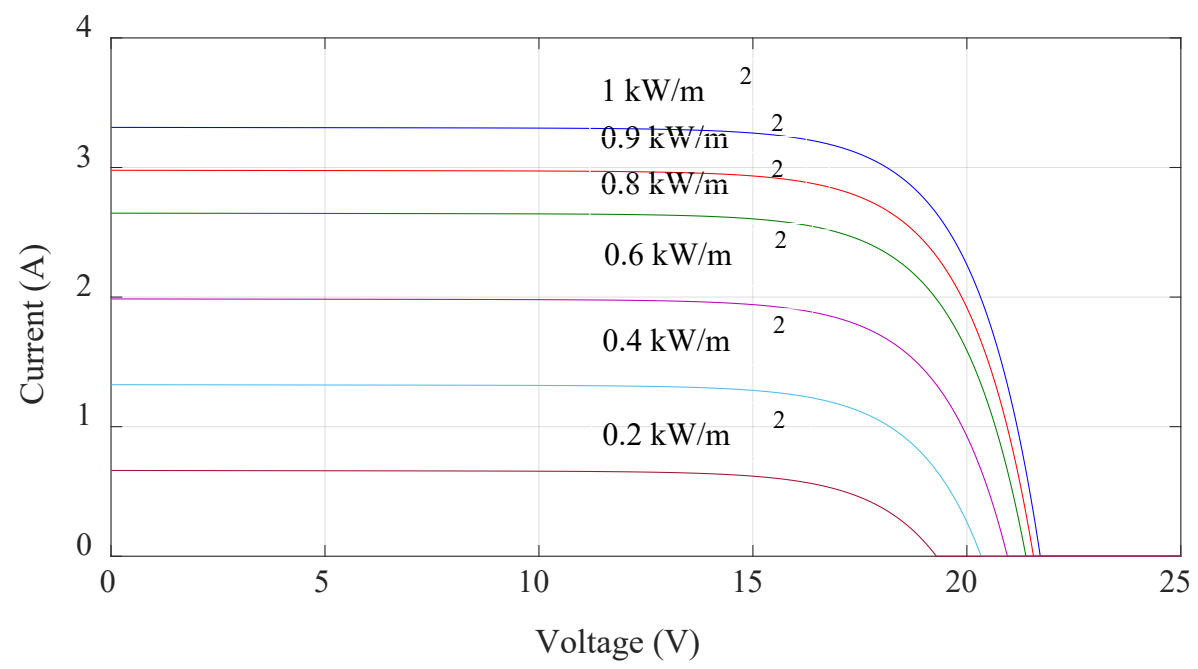

Figure 2. I-V characteristics of solar cell under different irradiances (at $25^{\circ} \mathrm{C}$ ). 


$$
G_{C}(s)=\frac{k_{p}}{\tau_{i} s}-k_{p}
$$

The proposed MPPT algorithm was aimed at achieving zero error by providing a reference voltage, $V_{\mathrm{pv}}^{*}$ as the working point of the solar cell. When the error rate was far from zero, then a large reference voltage was given to reach the set point quickly, and when the error rate was close to zero, a small change in the reference voltage was given to prevent oscillations. The proposed MPPT algorithm was designed to provide a reference voltage for two different purposes. First, a large reference voltage with constant changes was used as an IP controller of the MPPT input to calculate the error. Second, a reference voltage with large changes was varied with the IP controller of the MPPT to quickly find the maximum power point that is working and to keep the system working at that point. The proposed MPPT required feedback from the plant in the form of the gradient of the P-V curve ${ }^{11}$. Since the P-V curve of a solar cell has nonlinear characteristics, the value of $\Delta \mathrm{P} / \Delta \mathrm{V}$ must be calculated by using a small value of $\Delta \mathrm{V}$. This is in contrast with the aim of varying a new actual value of $\Delta \mathrm{V}$. Therefore, in this MPPT design, the reference voltage was updated alternately by the PI controller and gradient timer. Figure 3 shows the block diagram of the new MPPT algorithm model.
For the solar cell to work at the maximum power point, the gradient of the P-V curve had to be close to zero. Therefore, the set point for the PI controller of the MPPT had to be constantly at zero, while its feedback was the gradient of the P-V curve itself. Based on the P-V curve in Figure 1, a positive gradient meant the working point was on the left of the MPP ${ }^{12}$. In this case, a reference voltage had to be added so that the negative gradient could be reduced. Therefore, the error of the PI controller or the MPPT was reversed, making the set point as the negative input, while the feedback controller was the positive input. The new formula was written as:

$$
\text { error }=I_{P V}+\frac{d I_{P V} V_{P V}}{d V_{P V}}
$$

where,

$d I_{P V}=$ change in current

$d I_{P V}=$ change in voltage

The equation and error input of the new IP-based MPPT is given in Equation (12). Therefore, the differential of the IP controller was as follows:

$$
V_{P V}^{*}=k_{1 i} \int\left(I_{P V}+\frac{d I_{P V} V_{P V}}{d V_{P V}}\right) d t-k_{1 p}{ }^{\star} V_{p v}
$$

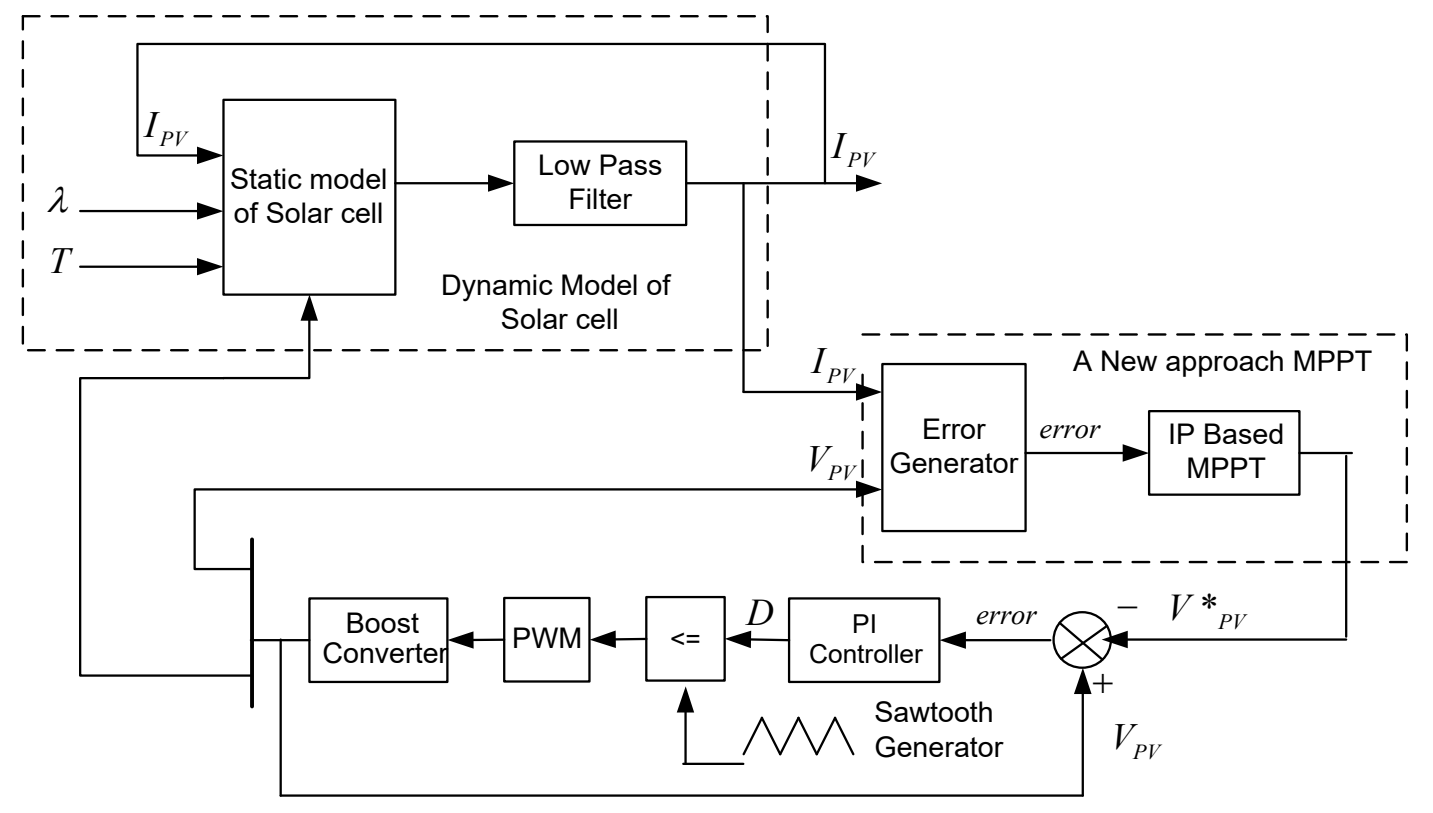

Figure 3. Block diagram of a new MPPT. 
By assuming,

$$
\frac{d}{d t} x_{1}=I_{P V}+\frac{d I_{P V} V_{P V}}{d V_{P V}}
$$

Hence,

$$
V_{P V}^{*}=k_{1 i} x_{1}-k_{1 p} * V_{p v}
$$

As for the second PI controller, the input error controller could be seen in the design of the system. As shown in Figure 3, the second differential equation of the PI controller was derived as:

$$
D=k_{2 p}\left(V_{P V}-V_{P V}^{*}\right)+k_{2 i} \int\left(V_{P V}-V_{P V}^{*}\right) d t
$$

by assuming

$$
\frac{d}{d t} x_{2}=V_{P V}-V_{P V}^{*}
$$

Then, by substituting Equation (15) into Equation (16), the following was produced

$$
\begin{gathered}
\frac{d}{d t} x_{2}=V_{P V}-\left(k_{1 i} x_{1}-k_{1 p} * V_{p v}\right) \\
\frac{d}{d t} x_{2}=V_{P V}-k_{1 i} x_{1}+k_{1 p} * V_{p v}
\end{gathered}
$$

Hence,

$$
D=k_{2 p} V_{P V}-k_{2 p}\left[k_{1 p} * V_{p v}-k_{1 i} x_{1}\right]+k_{2 i} x_{2}
$$

\section{Simulation Results}

The main component parameters of the boost converter circuit and PI controller implemented in the MATLAB Simulink are given in Table 1. A vital component of the reference solar cell used in this research was the solar cell model KC50T manufactured by Kyocera (Kyocera KC50T Datasheet), with the parameter specifications as given in Table 2.

The measurements shows Figure 4 of the oscillations of the boost converter circuit with the MPPT algorithm getting no closer to the Maximum Power Point (MPP), except away from it. The solar cell temperature was set at standard conditions at $25{ }^{\circ} \mathrm{C}$, while the solar radiation was changed from $400 \mathrm{~W} / \mathrm{m}^{2}$ to $1000 \mathrm{~W} / \mathrm{m}^{2}$ in the
Table 1. Simulation Parameters

\begin{tabular}{|l|l|l|}
\hline \multicolumn{2}{|l|}{ Component of Boost Converter Circuit } & \multicolumn{1}{l|}{ PI Controller } \\
\hline $\mathrm{L}$ & $100 \mu \mathrm{H}$ & $\mathrm{Kp}=0.03$ \\
\hline fs & $20 \mathrm{kHz}$ & $\mathrm{Ti}=0.0006$ \\
\hline $\mathrm{Vc}$ & $400 \mathrm{Volt}$ & $\mathrm{dt}=0.0001$ \\
\hline $\mathrm{Vd}$ & $0.62 \mathrm{Volt}$ & \\
\hline $\mathrm{RL}$ & $0.15 \Omega$ & \\
\hline C & $820 \mathrm{uF}$ & \\
\hline Ns & $15 \mathrm{cells}$ & \\
\hline
\end{tabular}

Table 2. Specifications of KC50T

\begin{tabular}{|l|l|}
\hline Characteristics & Values \\
\hline \multirow{2}{*}{ Maximum Power(P max) } & $+10 \%$ \\
\cline { 2 - 2 } & $54 \mathrm{Watt}$ \\
\cline { 2 - 2 } & $-5 \%$ \\
\hline Open circuit PV voltage $\left(\mathrm{V}_{\mathrm{OC}}\right)$ & $21.7 \mathrm{~V}$ \\
\hline Short circuit PV current $\left(\mathrm{I}_{\mathrm{SC}}\right)$ & $3.31 \mathrm{~A}$ \\
\hline $\begin{array}{l}\text { Open circuit voltage in temperature } \\
\text { coefficient }\left(\mathrm{V}_{\mathrm{OC}}\right)\end{array}$ & $-8,21 \times 10^{-2} \mathrm{~V} /{ }^{\circ} \mathrm{C}$ \\
\hline $\begin{array}{l}\text { Short circuit in temperature coefficient } \\
\left(\mathrm{I}_{\mathrm{SC}}\right)\end{array}$ & $1,33 \times 10^{-3} \mathrm{~A} /{ }^{\circ} \mathrm{C}$ \\
\hline Maximum power PV voltage $\left(\mathrm{V}_{\mathrm{MPP}}\right)$ & $17,4 \mathrm{~V}$ \\
\hline Maximum Power Current $\left(\mathrm{I}_{\mathrm{MPP}}\right)$ & $3.11 \mathrm{~V}$ \\
\hline Cell in series per module & 36 \\
\hline
\end{tabular}

third second. When the solar radiation increased in the third second, the MPP working point of the solar cell also increased. However, before the working point of the solar cell increased, the output voltage dropped for 0.2 seconds because the VREF given by the MPPT algorithm was lower than the output voltage of the boost converter. This can be understood by looking at the measurements of the boost converter circuit. This shows the potential of the MPPT to overcome the drawbacks of the PIMPPT. Figure 5 shows the output current $I_{p v}$ measured on the boost converter circuit.

The VREF was updated to calculate the error input at the PI MPPT or if the new MPPT value was small, constant or positive. If the output voltage had increased, likewise they would have subsided automatically, as shown in Figure 1. These oscillations occurred because when the algorithm calculated the error for the PI controller input, there was an increase in solar radiation at the same time. 


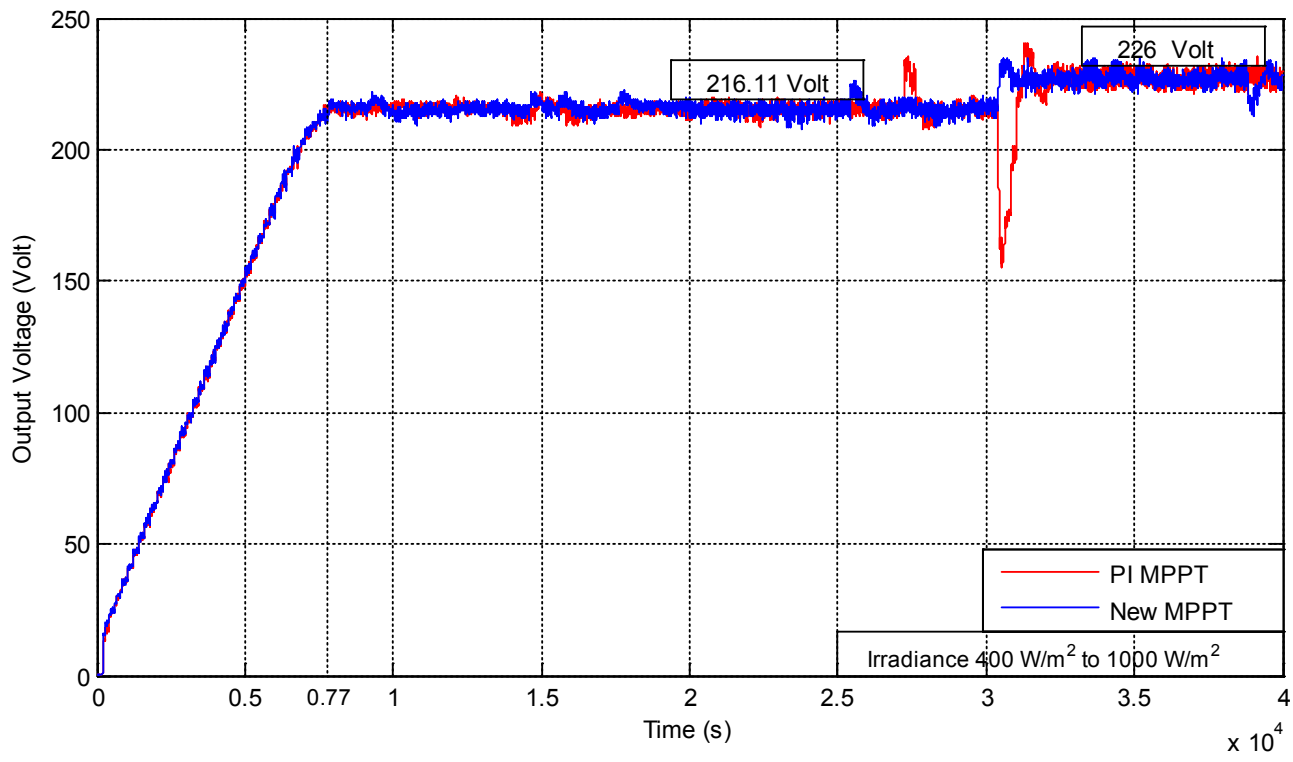

Figure 4. Output Voltage of PI MPPT and new MPPT.

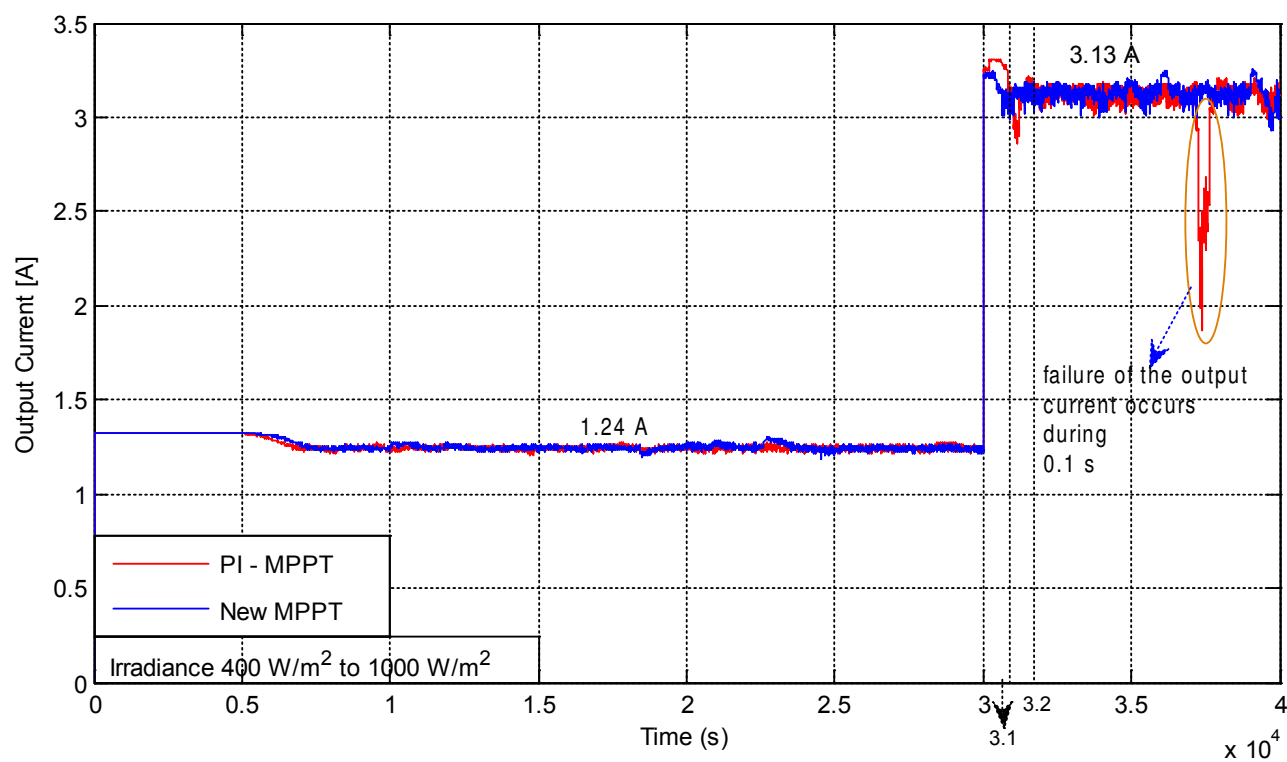

Figure 5. Output Current of PI MPPT and new MPPT.

The increase in solar radiation increased. The error calculation involved the increase in the Therefore, They should have been smaller, but since there was an increase in solar radiation, they became even greater. This caused an error in calculation, and thus, the VREF given by the IP-based MPPT algorithm was also wrong. This shows that when there is a gradient or a PIMPPT controller input error in the event of oscillations, the value of the gradient becomes very extreme. As such, it can be used as a parameter for detecting oscillations. An anti-windup was added into the proposed algorithm to reduce the effects of the extreme error.

The Figure 6 shows output power produced by the proposed MPPT system in standard environmental con- 


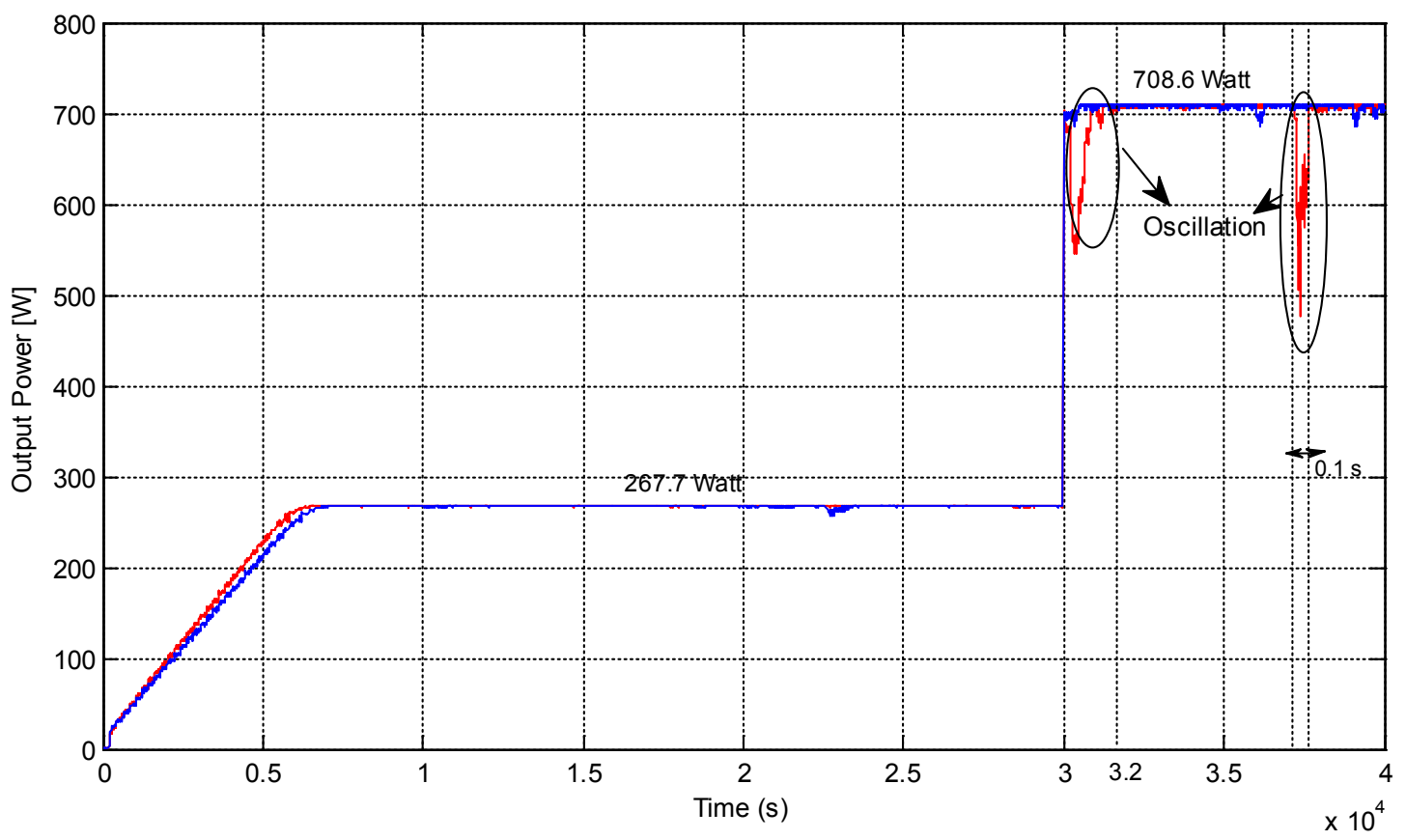

Figure 6. Output Power of PI MPPT and new MPPT.

ditions. The power generated was around 708.6 Watt. The oscillation power derived from the system was smaller than that generated by the PI MPPT. The power obtained from the voltage-current weakened each other, so there were small oscillations in the output power.The amount of energy (Joule) is calculated as follows:

$$
E(t) \int_{0}^{t} P_{p v} v(\tau) d \tau
$$

It was found that overcoming the oscillation for $0.3 \mathrm{sec}-$ onds was able to save a loss of approximately $30 \%$ in energy. Overall, the MPPT system was capable of finding the maximum power point and maintaining the working of the solar cell at that point. Basically, the boost converter model had a natural ripple that did not come from the MPPT algorithm, but instead was caused by the PI MPPT controller, making it difficult to achieve steady state conditions. By using the proposed MPPT, the oscillations could be reduced.

\section{Conclusion}

In this paper, a new approach to MPPT was conducted to extract the maximum output power of a solar cell system under sudden change conditions. The method used an indirect MPPT control topology which incorporated two controllers. The reference voltage-based MPPT was implemented by combining it with a Proportional Integral (PI) controller as an inner controller. A new duty ratio was derived from the proportional integral controller to boost the DC-DC converter to adjust the $\mathrm{PV}$ terminal voltage. A mathematical model was used to implement the $P-V$ characteristic under sudden change conditions. The new MPPT algorithm was verified by using MATLAB/ Simulink simulations. The PV system was implemented using the proposed MPPT. The results showed that the proposed MPPT was able to reach the MPP and eliminate the oscillations under sudden change conditions. Moreover, the controller indicated a fast converging speed, with small oscillations around the MPP during steady state conditions. Furthermore, approximately $30 \%$ of energy could be saved in 0.3 seconds.

\section{Acknowledgements}

The authors would like to thank the MOHE (Ministry of High Education of Malaysia), UTM under Research No.4F890, the Malaysia-Japan International Institute of Technology (MJIIT), and University Teknologi Malaysia Kuala Lumpur for providing some of the facilities for carrying out this research. 


\section{References}

1. Liu F, Duan S, Liu F, Liu B, Kang Y. A Variable Step Size INC MPPT Method for PV Systems. IEEE Transactions on Industrial Electronics. 2008; 5(7):2622-28.

2. Liu F, Kang Y, Zhang Y, Duan S. Comparison of P\&O and Hill Climbing MPPT Methods for Grid-Connected PV Converter. IEEE Industrial Electronics and Applications. 2008; p. 804-807. PMid:19070496

3. Kumar H, Tripathi RK. Simulation of Variable Incremental Conductance Method with Direct Control Method Using Boost Converter. IEEE Engineering and Systems (SCES), 2012 Students Conference on. 2012; p. 1-5. crossref

4. Kuo Y, Liang T, Chen J. Novel Maximum-Power-PointTracking Controller for Photovoltaic Energy Conversion System. IEEE Transactions on Industrial Electronics. 2001; 48(3):594-601. crossref

5. Koizumi H, Mizuno T, Kaito T. A Novel Microcontroller for Grid-Connected Photovoltaic Systems. IEEE Transactions on Control Systems Technology. 2006; 53(6):1889-97. crossref

6. Li X, Li Y, Seem JE. Maximum Power Point Tracking for Photovoltaic System Using Adaptive Extremum Seeking Control. IEEE Transactions on Control Systems Technology. 2012; 21(6):1-8.
7. Rauschenbach HS. Solar Cell Array Design Handbook. New York: Van Nostrand Reinhold. 1980; p. 111-51. crossref crossref

8. Pindado S, Cubas J, Sorribes-Palmer F. On the Analytical Approach to Present Engineering Problems: Photovoltaic Systems Behavior, Wind Speed Sensors Performance, and High-Speed Train Pressure Wave Effects in Tunnels. Hindawi Publishing Corporation. 2015; p. 1-17.

9. Yap WK, Karri V. An off-grid hybrid PV/diesel model as a planning and design tool, incorporating dynamic and ANN modeling techniques. Renew Energy. 2015; 78:42-50. crossref

10. Radjai T, Gaubert JP. The New FLC-Variable Incremental Conductance MPPT with Direct Control Method Using Cuk Converter. IEEE. 2014; p. 2508-13. crossref

11. kumaran SR, Kumar YS, Gupta R, Kumaran SR, Kumar YS, Gupta R. Global Maximum Power Point Tracking of Multiple PV Modules under Partially Shaded Condition Using Stepped Comparison Search Global Maximum Power Point Tracking of Multiple Photovoltaic Modules under Partially Shaded. Electric Power Components and Systems. 2016; 44(12):1384-95. crossref

12. Figueres E, Member A, Garcerá G. Sensitivity Study of the Dynamics of Three-Phase Photovoltaic Inverters with an LCL Grid Filter. IEEE Transactions on Industrial Electronics. 2009; 56(3):706-17. crossref 